\title{
HEPATITIS E: ZOONOTIC PERSPECTIVES
}

\author{
Ambreen Aisha ${ }^{1}$, Arooj Arshad ${ }^{2}$, Farwa Batool ${ }^{3}$ and Tahira Muneeb ${ }^{1}$ \\ ${ }^{1}$ Biochemistry Department, Faisalabad Medial University, Faisalabad \\ ${ }^{2}$ Biochemistry Department, University of Agriculture, Faisalabad, Faisalabad \\ 3Pathology Department, Faisalabad Medial University, Faisalabad \\ *Corresponding author: aishafmu@gmail.com
}

\section{INTRODUCTION}

Hepatitis E virus (HEV) is a single stranded hepatotropic virus which primarily affects the liver, resulting in acute hepatitis in humans. Every year, approximately 20.0 million HEV infections are reported globally, with 3.3 million symptomatic cases. The infection results in 3.0 million acute cases and 57,00o deaths per year (WHO, 2020).

Infection caused by HEV may be severe, ranging from imperceptible infection to fulminant liver and, if untreated, can lead to death. It was previously considered as an acute infection; however, chronic infections have also been observed in people suffering from chronic liver disease (CLD) and kidney or liver transplant. Despite the growing awareness about the HEV, the origin of the disease remains complicated to understand (Guerra et al. 2017). The HEV was first reported in 1983 by a Russian virologist (Balayan et al. 1983), who examined the virus under electron microscope while investigating his own feces after intake of a pooled fecal extract of soldiers, who were previously infected by the virus.

The virus enters the human body through the intestine, while it is eliminated in the stools of infected persons. The infection is generally self-limiting and resolves within 2-6 weeks. In the past, HEV was not considered to be prevalent in developed countries. However, now-a-days, it is believed to be endemic, as it is observed to be a zoonotic contagious agent in many developed countries. In these countries, acute hepatitis is commonly caused by autochthonous infections due to $\mathrm{HEV}_{3}$ and $\mathrm{HEV}_{4}$. The available literature shows that in previous years the most frequent genotype in China was $\mathrm{HEV}_{1}$, but due to improved hygiene and sanitation conditions, $\mathrm{HEV}_{4}$ surpassed HEV1 (Dai et al. 2013).

With regard to developing countries, waterborne acute hepatitis occurs due to HEV. Furthermore, the infection is more prevalent in areas with poor sanitation and hygiene conditions. Since HEV is a single stranded RNA, it exhibits high rate of mutations in genome, which has been estimated from clinical isolates in previous studies. The mutation rate of HEV has been observed to be more than 1.5 base substitutions per site in a year, which is comparable to that reported for hepatitis $\mathrm{C}$ virus (HCV). Novel HEV variants in different animals have been identified, which is constantly evolving the diversity of the virus. This chapter will discuss about the basic virology, genotypes of $\mathrm{HEV}$, epidemiology, zoonotic transmission, diagnosis, clinical complications, and treatment of the infection, based on the currently available data.

\section{Basic Virology of Hepatitis E virus}

Hepatitis E virus is currently the only species classified within the genus Hepevirus, family Hepeviridae. The hepatitis E virion is non-enveloped and $27-35 \mathrm{~nm}$ in size. The viral genome consists of three partially overlapping open-reading frames (ORFs) (Nagashima et al. 2017), as shown in Fig. 1a.

\section{ORF1}

ORF1 encodes non-structural polypeptides i.e. methyltransferase, RNA helicase, cysteine protease and RNA-dependent RNA polymerase activity (Fig. 1b). The $\mathrm{PORF}_{3}$ and $\mathrm{pORF}_{2}$ encode for sub-genomic RNA fragment of $2.2-\mathrm{Kb}$ into two different reading frames.

\section{ORF2}

The viral capsid $\mathrm{ORF}_{2}$ is translated into a multifunctional $88 \mathrm{kDa}$ protein with 660 amino acids, which is helpful in encapsculating viron and maintaining host viral interaction.

\section{$\mathrm{ORF}_{3}$}

$\mathrm{ORF}_{3}$ encodes for a phosphoprotein carrying 114-amino acids with molecular weight of $13-\mathrm{kDa}$. This protein bears proline rich residues, which interact with $\mathrm{SH}_{3}$ domain and MAPK (mitogen activating phosphokinase factor) of the host to mediate cellular response. Viral genomic fragment $\mathrm{PORF}_{3}$ transcribes by regulating MAPK/ERK and JAK/STAT pathways via epidermal growth factor receptor (EGFR), which thereby hinders immune activation. In addition, $\mathrm{pORF}_{3}$ is supposed to play a vital role in budding of virion by Golgi synthesis (Ikram et al. 2018).

Identified mutations of $\mathrm{ORF}_{1}$ and $\mathrm{ORF}_{2}$ regions of HEV are shown in Fig. 1. The box numbers represent the amino acid position; the letters above the box refer to the wild type amino acid and the letter below the box are relevant mutations cited before (Ikram et al. 2018). During genotyping of HEV, it was revealed that genotype 1 possessed 8 sites of mutation compared with genotypes 3 and 4 , which possess only 6 and 3 mutations, respectively. 


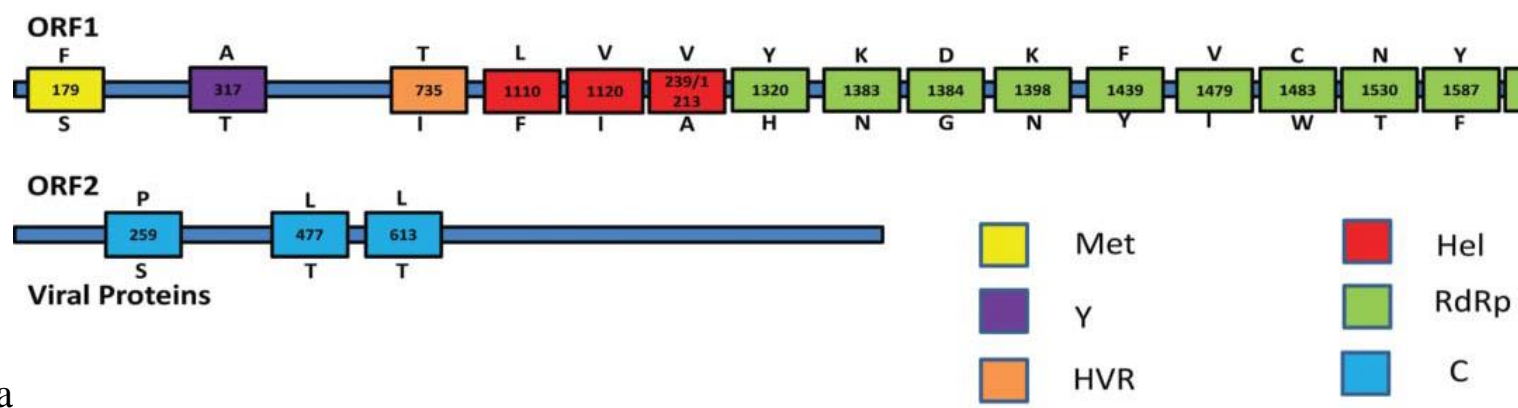

a

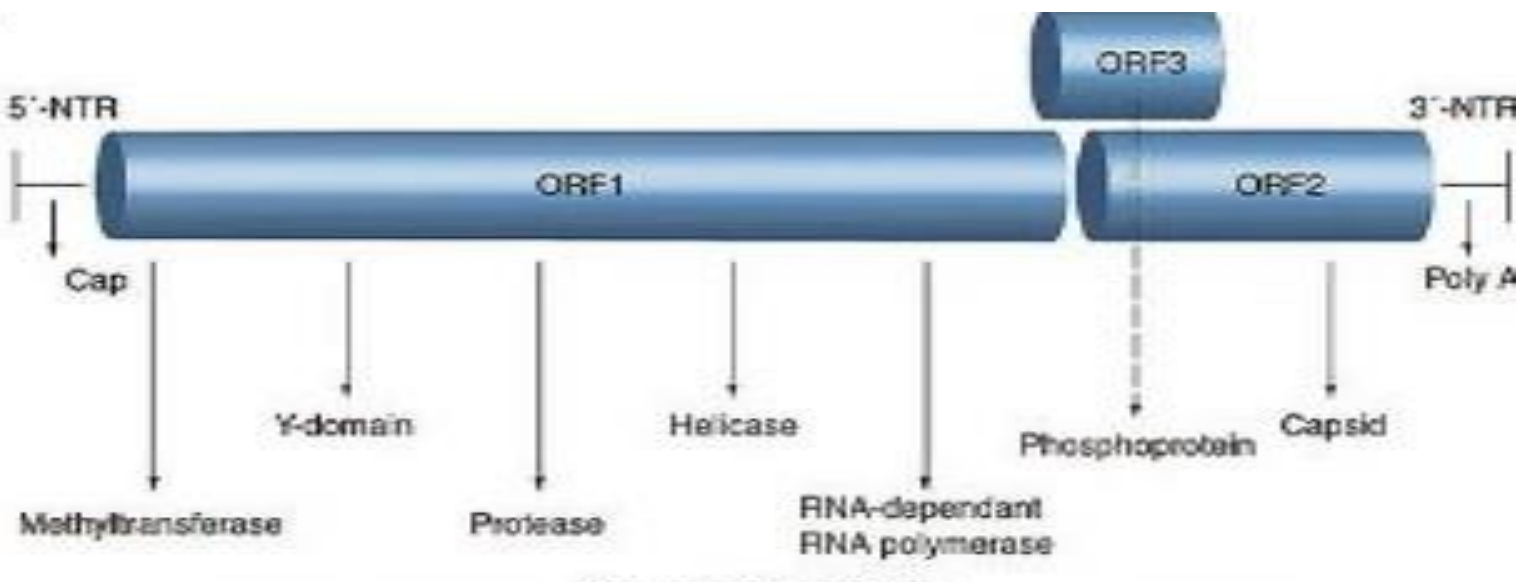

Genomic Arva $\{-7.5 \mathrm{~kb}\}$

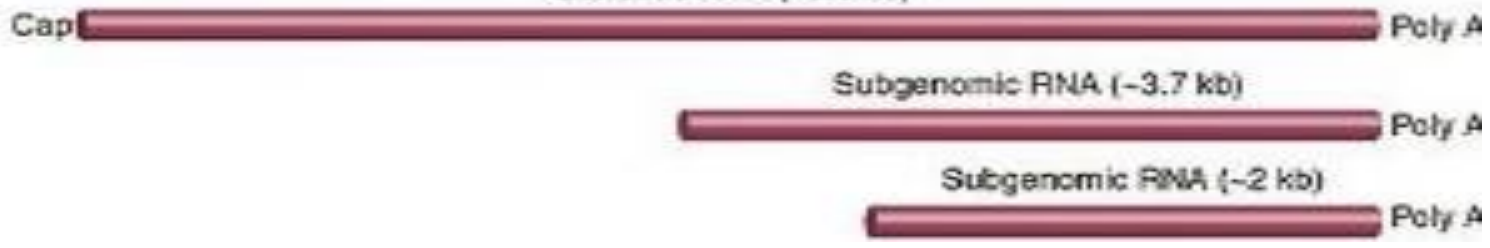

Fig. 1a: Mutagenic regions of open reading frame (ORF) 1 and 2 of Hepatitis E virus (Hel: RNA helicase; RdRP: RNA-dependent RNA polymerase; C: capsid protein, Met: methyltransferase; Y: Y-domain; HVR: hypervariable regions). 1b: Three main ORF with their genomic regions for Helicase, capsid methyltransferase etc.

\section{Epidemiological aspects of Hepatitis E}

HEV infection in humans has two different epidemiological designs. The virus is responsible for the worldwide transmission of hepatitis and has caused higher than $50 \%$ of acute hepatitis cases in endemic countries. Contaminated water in unhygienic areas is the foremost cause of transmission of $\mathrm{HEV}_{1}$ and $\mathrm{HEV}_{2}$ in people through the fecal-oral route. Previous studies demonstrate that poor quality of water has resulted in a large number of sporadic cases and large outbreaks. Although HEV is self-limiting, it can lead to the development of liver failure, particularly in pregnant females. Moreover, patients having solid organ transplant or taking immunosuppressant and HIV patients suffering from AIDs can experience cirrhosis due to HEV infection (Labrique et al. 2010). Screening strategies have been significantly improved and periodic cases were observed in previous years due to zoonotic transmission of $\mathrm{HEV}_{3}$ and $\mathrm{HEV}_{4}$ through animal reservoirs.

One of the most common reasons for acute liver infection world-wide is HEV (Hepatitis E virus). In India, HEV is responsible for more than $50 \%$ of acute viral infection in liver, while $25 \%$ in Africa and $15-20 \%$ in Eastern-Oriental countries.
HEV was originally recognized like non-A non-B hepatitis, which creates infection through water borne illness like hepatitis A (Donnelly et al. 2017), and epidemics in developing countries are mainly connected with genotypes 1 and 2 . However, currently it is the prominent reason of icteric hepatitis and acute failure of liver in underdeveloped areas around the world, the predicted occurrence of HEV illnesses is 20 million per anum, which can result in about 56,600 mortalities (Lozano et al. 2012). A major instance during severe infection is in pregnant women, who are more vulnerable and may exhibit the clinical development linked with poor results (300o stillbirths are annually recorded due to $\mathrm{HEV}_{3}$ ). Genotypes 3, 4 and 5 are involved in locally acquired HEV infections since the last decade in western countries. However, since 2008, chronic HEV infections are considered (Kamar et al. 2008) and this may cause cirrhosis and organ failure in transplant recipients (Kamar et al. 2011). It has been suggested that in developed countries, HEV pathogen is underconsideration, while frequency of confirmed cases has also been reported (Koot et al. 2015; Adlhoch et al. 2016). According to various cohort studies, seroprevalence rate HEV infection was reduced in some countries (Wenzel et al. 2014; Holm et al. 2015), whereas few have reported 
increased ratio of (HEV-RNA-positive) blood donors (Hogema et al. 2014; Tedder et al. 2016). World Health Organization (WHO) have reported through systemic review the range ofo.o3\% to $52 \% \mathrm{HEV}$ seroprevalence (having IgG antibody) in general population and blood donors. However, in 2014, WHO reported the maximum incidence of HEV seroprevalence in France and Netherlands. In European countries, there are $77 \%$ patients having symptomatic acute hepatitis through HEV infection and show a significant relation of the virus with liver morbidity (WHO 2014). However, seroprevalence estimation was remarkably affected through the use of different serological test systems.

Hartl et al. (2016) conducted a research through which they observed HEV illness during 1983-2015 around UAE, North and East Africa and Pakistan in Dromedaries. For this purpose, serum and fecal samples were collected from dromedary camels in the UAE, Somalia, Sudan, Egypt, Kenya, and Pakistan during 1983-2015 (Aggarwal 2016; Lee et al. 2016). Through RT-PCR (reverse transcription PCR), analysis of 2,171 serum samples and 267 fecal samples for HEV RNA was done (Drexler et al. 2012). The positive serum samples (about $46 \%$ from 6 countries) were compared with the seroprevalences characteristically seen in pigs responsible for zoonotic reservoirs of HEV-3 in developed countries (Krumbholz et al. 2012). Another study reported the occurrence of nonA, non-B liver illness, which was present in an armed academic community in Abbottabad, Pakistan. This was due to an isolate of HEV genetically different from the HEV type responsible for an epidemic in Sargodha, (Pakistan). Genetically, the HEV strains isolated from Sargodha resembled the isolates from China around Hindu Kush hills from Pakistan. However, the type isolated from Abbottabad genetically resembled with south Asian isolated strain from Nepal, India and Burma (Cuyck-Gandre et al. 200o). Therefore, two genetically different HEV strains were responsible for hepatitis $\mathrm{E}$ infection in the Pakistani military.

\section{HEV Genotypes}

$\mathrm{HEV}$ is a non-enveloped, positive-sense, RNA virus (Emerson et al. 2010), which is approximately $7.2 \mathrm{~kb}$ long and 27 to $34 \mathrm{~nm}$ in diameter, and is capped with $7^{-}$ methylguanylate at $5^{\prime}$ and polyadenylated at 3' end (Kabrane-Lazizi et al. 1999; Debing et al. 2016). It is comprised of a short 5 ' untranslated region (UTR), three open reading frames (ORFs), namely ORF1, ORF2 and $\mathrm{ORF}_{3}$, and a $3^{\prime}$ UTR. Non-structural proteins, as well as methyltransferase, cysteine protease, RNA-dependent RNA polymerase and helicase, are encoded by ORF1, (Koonin et al. 1992). ORF2 encodes the viral capsid protein, whereas a phosphorylated protein (113 or 114 amino acids long) is encoded by $\mathrm{ORF}_{3}$, which plays an important role in morphogenesis and release of the virus (Emerson et al. 2010). Frameshifted segments from a sub genomic mRNA species are encoded by overlapping reading frames $\mathrm{ORF}_{2}$ and $\mathrm{ORF}_{3}$ (Graff et al. 2006). Interspecies variation was observed at the junction of both frames, with the variant cutthroat trout virus comprising of an $\mathrm{ORF}_{3}$, which is displaced towards the core of ORF2 (Siddharth et al. 2017).

HEVs found in humans are sub-catagorized in the genus Orthohepevirus and species Orthohepevirus A (Smith et al. 2014). Nucleotide sequencing of HEV genome from samples isolated from humans and animals made it clear that Orthohepevirus A viruses can be grouped into 8 genotypes (HEV-1 to $\mathrm{HEV}-8)$, which are further subdivided in subtypes (Enouf et al. 2006).

While $8 \mathrm{HEV}$ genotypes have been identified, there are 4 distinct genotypes, including genotype 1, 2, 3 and 4 , that infect humans. Genotypes 1 and 2 are present in humans (usually found in young and adults, aged 15-40), causing self-limited acute infection, which can hardly become chronic. In developing countries, these genotypes contribute the most to cause the infection. Previous findings suggest that animals, like wild deer, boars and pigs, carry genotypes 3 and 4 which are thought to be the primary causative agents of periodic infection in the developed countries and are transferred to humans by consuming raw meat of animals, such as pig and dear, and are mainly found in United States, China, Australia and Japan (Woo et al. 2016). These genotypes are mainly seen in older adults, who are above 40 years of age ( $\mathrm{Lu}$ et al. 2006), and they usually cause acute infections which can lead to chronic diseases in some cases.

Furthermore, Genotype 3 is divided into 10 sub genotypes, ranging from $3 \mathrm{a}-3 \mathrm{j}$, while genotype 4 is divided into 7 ( $4 \mathrm{a}-$ 4g) sub genotypes, and both are found in swine and humans. Although viral factors play an important role in the pathogenesis of the disease, condition of immune system of the host determines the severity of acute hepatitis (Rutjes et al. 2009). Hence, genotype of HEV contributes to the pathogenesis of HEV-associated hepatitis. It has also been observed that people infected with genotype $\mathrm{HEV}_{4}$ show more severe form of viral hepatitis than genotype $\mathrm{HEV}_{3}$ infected patients. Thus, genetic changes in HEV genotypes have a profound impact on the efficacy of viral transmission and, eventually, the severity of HEV-associated hepatitis. A single case of infection by genotype 7 has also been reported, but it is still unidentified that either this genotype is easily transmitted to humans or its transmission occurs only in exceptional cases (Lee et al. 2016). Genotype 8 was found in Bactrian camels from Xinjiang, China (Woo et al. 2013).

\section{Genotypes 1 and 2 Infection}

In underdeveloped countries, HEV isolates with genotypes 1 and 2 are more endemic; Genotype 1 is mostly responsible for acute liver infection in Asia (especially in India), while genotype $\mathbf{2}$ is predominant in Africa, Central America and Mexico. However, these genotypes are limited to humans. Data received from 9 out of 21 Global Disease Burden areas world-wide showed that out of 20.0 million HEV infections, around 3.3 million had $\mathrm{HEV}$ symptoms, with 56,60o HEV associated expiries according to the World Health Organization (WHO) findings, while 
the exact burden of disease is drastic. However, genotypes 1 and 2 are more responsible for infection in underdeveloped countries, with fatality rate ranges from 0.2 to $4.0 \%$. This mortality rate is about $20 \%$ in infected pregnant patients in endemic countries. A novel study designed on human liver cells on chimerical mice for HEV illness proved that intravenous injection of $\mathrm{HEV}$ virions was consequently excreted through stool. There was HEV genotype 1 infection, while there was no active $\mathrm{HEV}$ infection by injecting HEV-positive serum intraperitonealy or via intravenous route (Allweiss et al. 2016). These results show that stool positive for $\mathrm{HEV}$ virion is due to HEV genotype 1.

\section{Genotype 3 and 4 Infection}

Both, human beings and animals are targeted for HEV isolates of genotypes 3 and 4. The highest prevailing infection in advanced countries is mainly due to HEV genotype 3. Pigs, deer and wild boar are responsible for this in comparison with genotype 1 and 2 . In South-East Asia, genotype 4 infection is more prevalent (Hoofnagle et al. 2012).

\section{HEV Zoonotic Transmission}

Initially, it was believed that HEV infection was limited to humans, responsible for deaths from 0.5 to $3.0 \%$ in general. However, this mortality approached $30 \%$ in pregnant women. But presence of HEV in pigs in 1997 reflects that there is variety of HEV hosts and it is truly zoonotic. There are 70,000 mortalities and 3,000 stillbirths (Holm et al. 2015) from nine out of 21 parts of the world recommended as GDB (global burden of disease) study.

Primarily, it was suggested that Hepatitis E was only confined to undeveloped countries (Khuroo and Khuroo, 2016). But after evidences of infrequent hepatitis $E$ infections in advanced countries, these findings became conflicted and showed an extended host range worldwide (Anheyer-Behmenburg et al. 2017).

\section{Cross specie transmission}

Hepatitis $\mathrm{E}$ has become one of the worst active and powerful animal-born viral illness (Dalton et al. 2015). In these countries, major way of transmission of HEV is from animal sources to humans via cross-species transmission (Pavio et al. 2015; Salines et al. 2017). However, HEV is not best known commonly in contrast to the other liver viruses, like hepatitis $\mathrm{B}$ and $\mathrm{C}$ viruses. But, mostly in developed countries, the sporadic hepatitis $\mathrm{E}$ cases may be transmitted from endemic areas or associated with the persons traveling from an endemic part, while they are not transmitted through conventional fecal-oral way. HEV may have less endemicity in advanced countries having unknown infectious reasons. The advancement of diagnostic tools for HEV and sero surveillance analysis on anti-HEV antibodies reflected high proportion (about $28 \%$ in few parts) in persons living in the US and other advanced states, which showed that hepatitis $\mathrm{E}$ is not pervasive. Analytical data showed that there are unidentified HEV infection sources and unknown noninfectious or less infectious $\mathrm{HEV}$ isolates also present in advanced countries.

In advanced countries, occasional cases of HEV infection were basically associated with the visitors to HEV-pervasive undeveloped countries (Abid et al. 1997). These persons were expected to infect through impure water drinking via travelling. But there is high autochthonous HEV infections in developed countries (Preiss et al. 2006). However, the exact causes for infection in autochthonous cases are still unknown and there are several risks which may be associated with this infection (Chaussade et al. 2013).

Evaluation of pervasiveness for anti-HEV antibodies to measure connection amongst HEV contagion risk and profession shows that there is significantly higher $\mathrm{HEV}$ seroprevalence in farmers than that in other professions in China (34.4\%) (Jia et al. 2005). It is about 1.5 times higher in persons (veterinarians) handling pigs than in standard blood donors in the USA (Moal et al. 2013). Additionally, there is 3.5 times greater danger for HEV infection in swine farmers than general people in rural Taiwan (Lee et al. 2016). Furthermore, the occurrence of serum HEV-reactive antibodies is also greater in persons working on swine-associated activities, like veterinarians, meat inspectors, pig farmers and slaughter houses than in registered blood donors in Spain and Germany (Galiana et al. 2008; Krumbholz et al. 2012). About $41.7 \%$ persons working in slaughterhouses are reported as carriers of serum HEV-reactive antibodies. All these findings reflect that persons who are in contact with pigs or other farm animals have great danger towards infection than those who are not associated with animals. However, currently, some authors claim that the HEV seroprevalence rates in people who are in contact with pigs are not remarkably higher in comparison with those people who are not in contact with pigs in Northern Thailand and Austria (Hinjoy et al. 2013; Lagler et al. 2014).

\section{Swine zoonotic transmission}

Women employed on swine farms are observed to have less $\mathrm{HEV}$ infection rates in comparison with common people in Guangdong province in China (Liang et al. 2014). These findings reveal the occupational effect in spreading the infection. Therefore, there is need for more studies to solve this conflict concerning the professional based hazard factors in HEV infection. The following clues give significance about the reasons of autochthonous HEV illness HEV sequences separated from hepatitis $E$ positive are nearly similar to the sequences of swine HEV isolates (Widén et al. 2011). Along with, swine HEV sequences in sera acquired from native Netherland's patients who had not moved to HEVendemic countries (Herremans et al. 2007).

\section{Zoonotic transmission by farm animals and meat}

It is generally believed that acute hepatitis $\mathrm{E}$ native infectious cases are caused by pork eating and same is true 
in Japan (Miyashita et al. 2012). These autochthonous illnesses are usually seen in middle-aged to elderly persons, who generally eat pork meat (Péron et al. 2006). HEV infection cases due to eating uncooked or undercooked pork are also found in other countries. Consequently, nowa-days, pigs are considered as the basic risk factor for HEV positive population in advanced countries. Furthermore, in European countries, HEV infection is recognized by pork liver sausage, and wild boar are considered as risk factors (La Rosa et al. 2011). In France, this sausage seems to contribute remarkably in HEV infection (Colson et al. 2010). Illness of human hepatocarcinoma is also due to HEV infection present in pork liver sausages and it is thought that the occurrence of this danger lies in usage of these sausages (Berto et al. 2013).

A study reported acute hepatitis E infection in a Korean citizen, who used raw bile juice of wild boar (Kim et al. 2011). In wild boar, the HEV-4 is responsible for this danger. However, meat from other animal as carrier of HEV-3 strains has been identified in both human beings and animals like, wild boars, deer, and swine in Hungary (Reuter et al. 2009).

Remarkably similar HEV infection sequences were recognized in both roe deer and human beings. In Japan, similarity in HEV infection was identified among wild boars, deer and hepatitis $\mathrm{E}$ infected persons fed on raw deer meat (Takahashi et al. 2004). These data specify that transmission of HEV among species is possible, and that wild animals like boars and deer take part in the transfer of HEV to human beings. However, both HEV genomes and infectious HEV particles have been testified in sewerage water tasters (Masclaux et al. 2013) and this wastewater may also pollute seawater and shellfish. Certainly, in Japan, an HEV-3 isolate was found in saline water and it showed similarity with the human strain (Ishida et al. 2012). Polluted saline water contain shellfish and its consumption can cause infection of about 4 million people annually (Shuval et al. 2003). Among the shellfish samples collected from coastal area of China, around $18 \%$ were infected with $\mathrm{HEV}_{-4}$ strains and again there was close association with swine and human strains (Gao et al. 2015). Additionally, oysters of about 8.7\% gathered from costal area having HEV in Korea also resembled with swine HEV in nucleotide sequence (Song et al. 2010). Various HEV infection cases in developed countries confirmed that another causative agent for HEV infections in humans is due to eating habits of shellfish (La Rosa et al. 2011), as shown in Fig. 2.

Together with all these findings, it appears that most of the HEV infections in humans are through eating of animal meat, meat products, and seafood, especially in advanced countries. Initially, it was considered that HEV spread among animals and humans is through fecal-oral route.

\section{Transmission via blood donors}

Furthermore, it is proposed that in HEV endemic countries, blood transfusions also take part in spreading the infection (Arankalle and Chobe 200o). This is due to the presence of HEV-specified antibodies and high levels of alanine aminotransferase (ALT) in HEV-negative persons after blood transfusion. This was also confirmed in one study on rhesus monkeys, where the monkeys were infected with acute hepatitis after blood transfusion from hepatitis E-viremic donors. Blood transfusionmediated transmission is also seen in autochthonous HEV infections currently observed in advanced countries where HEV is not a zoonotic pathogen. Cases are reported after blood transfusion from HEV positive blood donors (Matsubayashi et al. 2004). Mostly, HEV infections are present basically in persons aged 15 to 45 years in HEV-prevalent areas, but studies also suggest that kids can also get infected with HEV via blood transfer (Colson et al. 2007). So, blood transfusion is now considered as a new risk factor for HEV transmission.

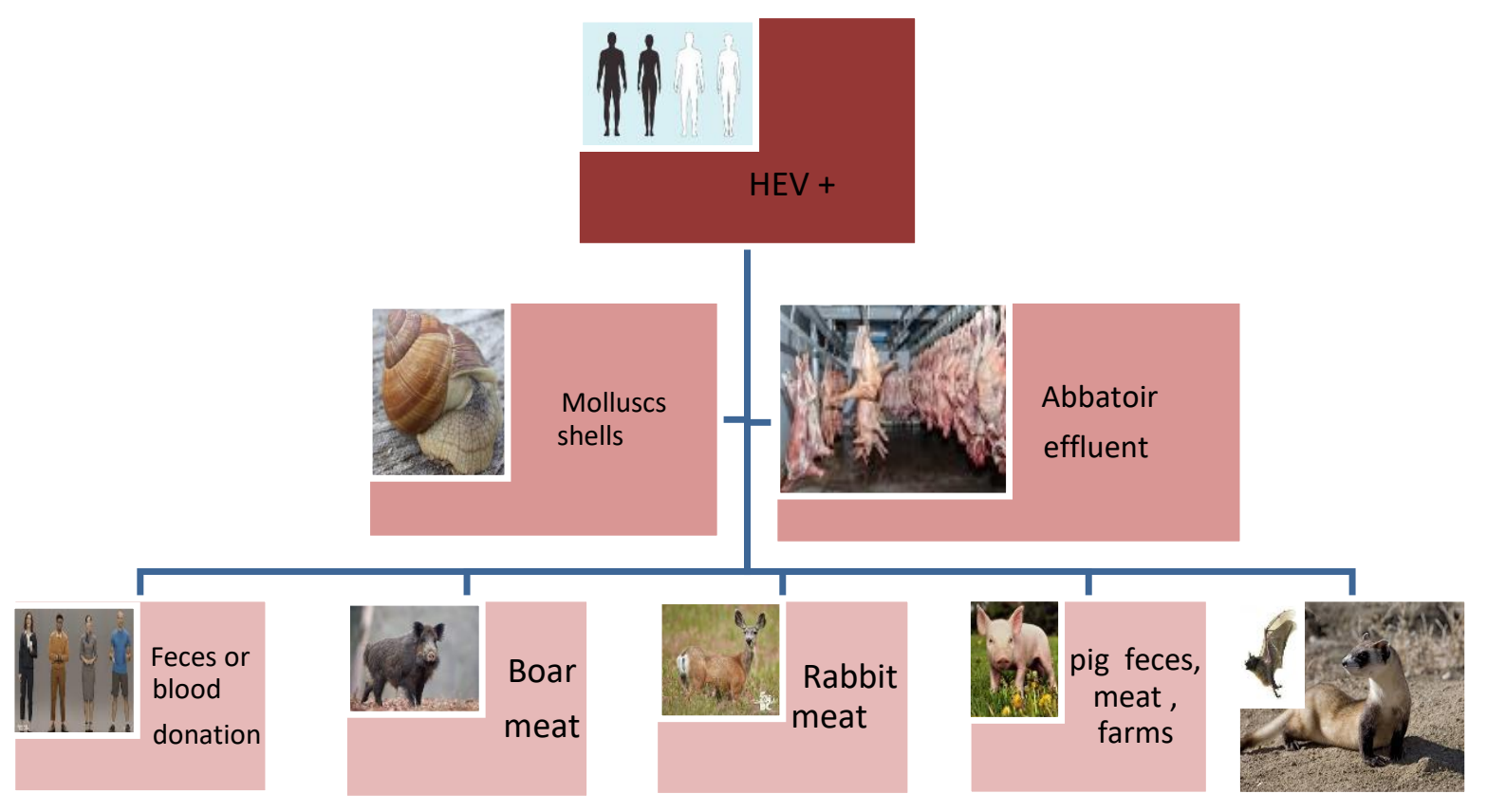

Fig. 2: Possible, probable, and definite routes of transmission of hepatitis E virus. 


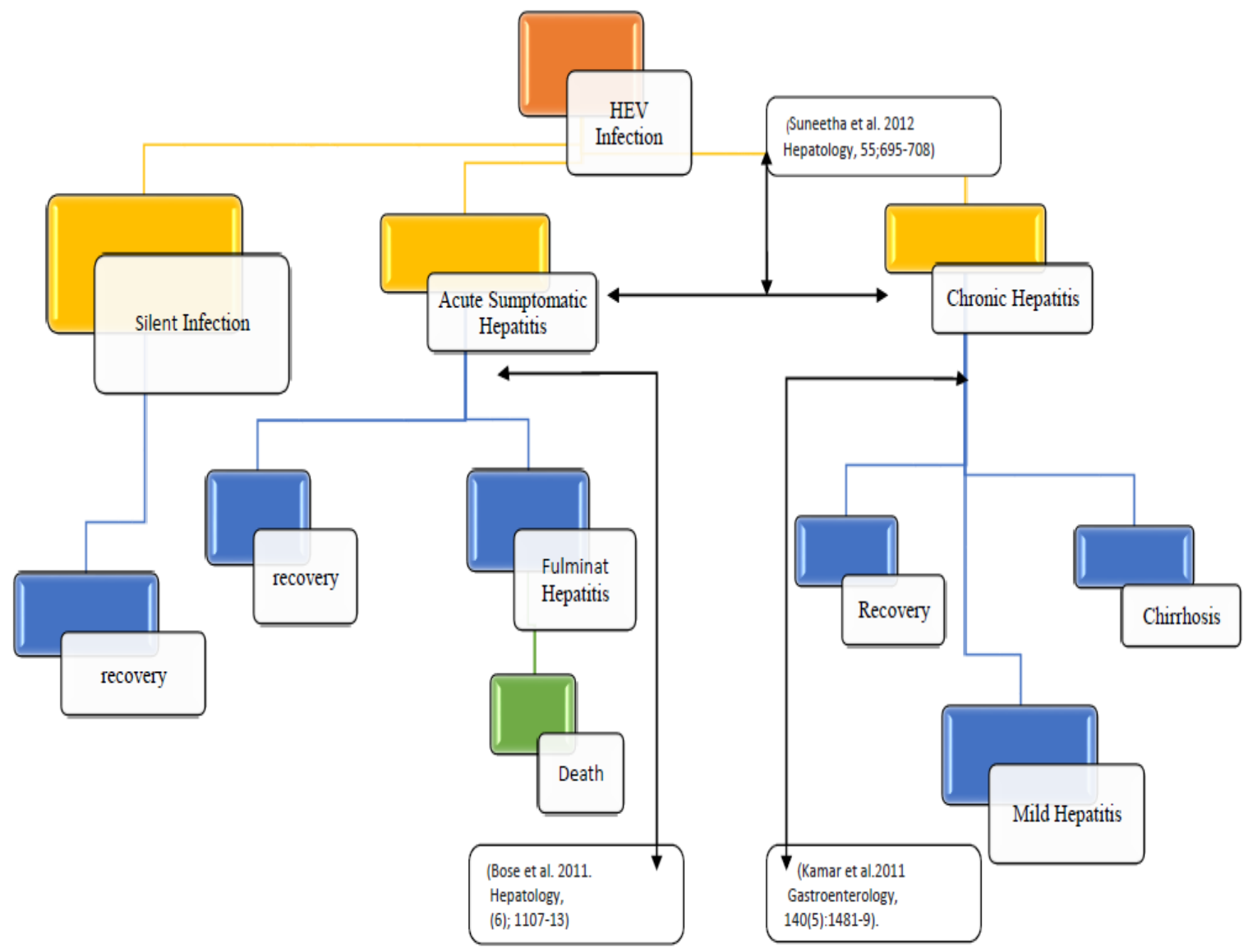

Fig. 3: Course of infection of Hepatitis E and its possible routes.

Table 1: Symptoms of acute autochthonous hepatitis E

\begin{tabular}{ll}
\hline Common symptoms & Less common symptoms \\
\hline Jaundice & Myalgia \\
Anorexia & Headache \\
Lethargy & Pruritis \\
Vomiting & Arthralgia \\
Abdominal pain & Neurological disorders \\
\hline
\end{tabular}

\section{Symptoms of Hepatitis E}

\section{Acute hepatitis $\mathrm{E}$ infection}

Mostly, viral hepatitis has common symptoms. As already mentioned, acute hepatitis E infection is a self-limiting disease, which requires conventional treatment (Dalton et al. 2014). Majority of patients are asymptomatic and their causes of illness are not completely identified, or they develop clinical signs and symptoms of acute hepatitis (viral), like malaise, anorexia, nausea, vomiting, jaundice, and abdominal pain (Table 1). Patient may present with the symptoms of acute jaundice with liver enlargement and tender abdomen. In case of fulminant hepatitis, adverse results of $0.5 \%$ fatality rate may be seen (Zhao et al. 2016).

\section{Chronic Hepatitis E}

Cases with severe hepatitis and underlying chronic liver disease have a poor prognosis (Dalton et al. 2008). Several of them have extrahepatic manifestations, such as thrombocytopenia, hemolysis, aplastic anemia, acute thyroiditis, membranous glomerulonephritis, and neurological diseases such as acute transverse myelitis and septic meningitis (Geurtsvankessel et al. 2013), as depicted in Fig. 3.

Other extra-hepatic signs and symptoms are also seen, which show the line of spectrum for other clinical complications. In UK and France, basically one of the main reasons for neurological disorder may be locally developed acute and chronic HEV infected persons. In hospitals, about $5.5 \%$ patients out of 126 , who were infected with acute hepatitis $\mathrm{E}$ virus, also showed neurological disorders during 2004 to 2009 (Kamar et al. 2011). Besides this, Sridhar et al. (2018) revealed that Guillain-Barre syndrome in China was also associated with this acute $\mathrm{HEV}$, while transplant patients also showed chronic infections. However, the occurrence of acute Hepatitis infection aspects in immuno-suppressed recipients is mostly due to the followings:

- Intensity of immune-suppression

- Time interval between last episode of acute rejection and HEV infection since the time of transplantation

- Reduced leukocyte and total-lymphocyte counts (Kamar et al. 2011).

\section{Serological Evaluation of Disease}

In clinical diagnosis of HEV infection, laboratory findings are fundamental. Elevated serum concentrations of aspartate aminotransferase (AST), bilirubin and alanine aminotransferase (ALT) are index for acute Hepatitis. 
Table 2: Vaccines derived from various candidate biological systems.

Pre-clinical evaluation of HEV vaccine candidates

\begin{tabular}{|c|c|c|c|c|}
\hline & ORF-2 protein & Amino acids & Source & Remarks \\
\hline \multirow[t]{3}{*}{ Expressed in E. coli } & TrpE-C2 & $221-660$ & Burma & \\
\hline & $\mathrm{pE} 2$ & $394-607$ & China & \\
\hline & HEV 239 & $368-606$ & China & Human CT \\
\hline \multicolumn{5}{|l|}{ Expressed in insect } \\
\hline \multirow[t]{2}{*}{ Baculovirus-mediated } & 56-kDa protein & $112-607$ & Pakistan & Human CT \\
\hline & 53-kDa protein & $112-577$ & Burma & Oral route \\
\hline \multirow[t]{3}{*}{ Spodoptera litura larvae } & $62-\mathrm{kDa}$ & $112-660$ & Burma & \\
\hline & $50 \mathrm{kDa}$ (VLPs) & $112-534$ & Burma & \\
\hline & $62-\mathrm{kDa}$ & $112-660$ & India & \\
\hline \multicolumn{5}{|c|}{\begin{tabular}{|l|l} 
Expressed in other system \\
\end{tabular}} \\
\hline Yeast Pichia pastoris & HBV/HEV & $551-607$ & China & \\
\hline Transgenic tomato plants & $\mathrm{pE} 2$ & $394-607$ & China & \\
\hline DNA vaccines & & & & Stability \\
\hline \multirow[t]{2}{*}{ Naked } & pJHEV & $1-660$ & Burma & Easy preparation \\
\hline & pcHEVORF2 & $1-660$ & Burma & \\
\hline DNA plus protein & $+26 \mathrm{kDa}$ & & India & \\
\hline
\end{tabular}

Serological analysis through ELlZA kits for anti-HEV IgM and IgG are available commercially (Cao et al. 2018). Diagnosis of acute HEV infection is performed with a positive serum HEV IgM in the proper clinical setting. Detection of HEV infection is confirmed by PCR of serum or stool samples. Testing through PCR should be the keystone of diagnosis in population; however, in immunecompromised individuals the antibody level is not high enough to produce PCR response (Khuroo and Khuroo 2016). In 2018, EASL (European Association for the Study of the Liver) recommended guideline for both nucleic acid amplification technique (NAT) and serum findings for the diagnosis of acute and chronic HEV infection (Dalton et al. 2014).

\section{HEV Molecular testing}

WHO International standards are available since 2011 for nucleic acid testing of HEV genotypes (Baylis et al. 2013). Conventional RT-PCR technique is used for investigation of HEV genotype. The latest marketed commercial HEV viral load assays provide better sensitivity (20-100 IU/ml) and specificity (Mokhtari et al. 2013). Previously, partialORF2 sequences were commonly employed for this purpose. Zhai et al. (2006) determined 306-base pair region of $\operatorname{RdRp}(\mathrm{ORF} 1)$ while completing statistically complete HEV genome bordered by conserved primer sequence (Dalton et al. 2014).

\section{Treatment/Management}

Acute Hepatitis E (HEV) infection mainly requires supportive care, as it is self-limiting. Within 6 weeks after onset of infection, the fate of course of Hepatitis E infection is resolved. Victims developing fulminant liver failure require transplantation of liver. Among Hepatitis E chronic patients which are immuno-compromised, amendment in immuno-suppressive medication and use of anti-viral drugs such as peginterferon along with ribavirin is recommended (Khuroo and Khuroo 2016; Kamar et al. 2020).

\section{Ribavirin}

Therapy with Ribavirin for the treatment of 9 chronic HEV transplant recipients showed no viral relapse after 5 months (Pischke et al. 2013). In cases of pregnancy, ribavirin is not recommended due to the risk of teratogenicity. The optimal daily dose of Ribavirin is suggested to be between 200 and 1,200 $\mathrm{mg}$ for less than 3 months according to virological response, depending on case situation (Koning et al. 2013). Important parameters like RNA clearance of HEV in plasma and ALT stabilizing to normal levels are monitored during the course of therapy (Versluis et al. 2013; Koning et al. 2013).

\section{Peg interferon}

HEV infection in immune-compromised patients is treated with Pegylated interferon-alpha-2a (Peg-IFN- $\alpha$ 2a) and oral ribavirin (Dalton et al. 2014).

\section{Hepatitis E vaccines}

At present for the prevention of Hepatitis E, commercial vaccines are under trial, which are of two types (depicted in Table 2).

\section{1- Recombinant vaccines}

2- $\quad$ Subunit HEV vaccines

HEV vaccine candidates, including recombinant neutralizing epitope protein in models of mouse and insect larvae-derived recombinant hepatitis E virus ORF-2 proteins, are being explored for their efficacy (Zhao et al. 2016). A vaccine of $56 \mathrm{KD}$ and HEV239 vaccine are under $2^{\text {nd }}$ and $3^{\text {rd }}$ phase of clinical trial (Zhu et al. 2010). HEV239 vaccine (Hecolin) is commercially presented in China (Nelson et al. 2014; Li et al. 2015), as mentioned in Table 2.

\section{HEV antigen in insect cell}

The HEV capsid antigen was expressed in Baculovirusinfected insect host system. The $56 \mathrm{kDa}$ candidate vaccine showed highly immunogenic effects in rhesus monkeys in 6 to 12 months (Cao et al. 2018).

\section{Proteins expressed in yeast}

HEV ORF2 protein is expressed in yeast after truncation. Research expressed truncated genotype IVHEV ORF2 (aa112-607) in a system of yeast Hansenulapolymorpha. The protein which was truncated exhibited high immunoreactivity, which provided the base for the

Table 3 : To date vaccines used for hepatitis E (Zhao 2016).

\begin{tabular}{cllll}
\hline Study of HEV & Region & Patient status & Feotal out comes & Protocol \\
\hline HEV vaccine & China 2007 & Pregnant women (No pre term delivery) & No congenital & HEV 239 (30ụg /per dose) at \\
& -2009 & Elective abortion 151\%, natural abortion. & anomalies & interval o, 1, 6 month \\
\hline
\end{tabular}




\section{Proteins expressed in yeast}

HEV ORF2 protein is expressed in yeast after truncation. Research expressed truncated genotype IVHEV ORF2 (aa112-607) in a system of yeast Hansenulapolymorpha. The protein which was truncated exhibited high immunoreactivity, which provided the base for the further advances in hepatitis $E$ recombinant vaccine development. Among plants, tomato is used as a carrier $\mathrm{HEV}$ ORF2 fragment. The plant binary expression vector p1301E2 was introduced into agrobacterium tumefaciens EHA105.87 for developing vaccine (Cao et al. 2018).

Up till now China has given shots of vaccine among pregnant patients of Hep E. Outcomes are shown in Table 3.

\section{Complications}

Several patients may develop complications like hepatic failure, cholestasis, jaundice or chronic hepatic failure. Some extrahepatic manifestations for HEV genotypes, such as encephalitis, peripheral neuropathy, GuillainBarre syndrome and ataxia, are being studied (Kamar et al. 2011). Yet vaccines have shown good results in their last trials.

\section{Conclusions}

In modern era, world has turned into a global village, hence HEV infection prevalence is not confined only to developing countries. Highly developed countries also suffer from endemic and zoonotic diseases. Following few aspects must be focused to develop guidelines for the intervention and management of Hepatitis E:

- Immune and hormonal factors of patients

- Genotypic heterogeneity of HEV

- HEV variants virulence

- $\quad$ Screening of voluntary blood donors (VBDs)

- Hygiene and healthy intervention

\section{REFERENCES}

Abid M et al., 1997. Hepatitis and travel abroad: A case report. Journal of Travel Medicine 4: 187-188.

Adlhoch C et al., 2016. Hepatitis E virus: Assessment of the epidemiological situation in humans in Europe, 2014/15. Journal of Clinical Virology 82: 9-16.

Aggarwal R, 2016. The global prevalence of Hepatitis E virus infection and susceptibility: A systematic review. http://whqlibdoc.who.int/hq/2010/WHO_IVB _10.14_eng.pdf

Allweiss L et al., 2016. Human liver chimeric mice as a new model of chronic hepatitis E virus infection and preclinical drug evaluation. Journal of Hepatology 64: 1033-1040.

Arankalle VA and Chobe LP, 20oo. Retrospective analysis of blood transfusion recipients: Evidence for posttransfusion hepatitis E. Vox Sang 79: 72-74.

Balayan MS et al., 1983. Evidence for a virus in non-A, non-B hepatitis transmitted via the fecal-oral route.
Intervirology 20: 23-31.

Baylis SA et al., 2013. World health organization international standard to harmonize assays for detection of hepatitis $\mathrm{E}$ virus RNA. Emerging Infectious Diseases 19: 729-735.

Berto A et al., 2013. Hepatitis E virus in pork liver sausage, France. Emerging Infectious Diseases 19: 264-266.

Cao Y et al., 2018. Development of new hepatitis E vaccines. Human Vaccines \& Immunotherapeutics 14: 2254-2262.

Chaussade $\mathrm{H}$ et al., 2013. Hepatitis E virus seroprevalence and risk factors for individuals in working contact with animals. Journal of Clinical Virology 58: 504-508.

Colson $\mathrm{P}$ et al., 2010. Pig liver sausage as a source of hepatitis $\mathrm{E}$ virus transmission to humans. Journal of Infectious Diseases 202: 825-834.

Cuyck-Gandre $\mathrm{H}$ et al., 200o. Short Report: Phylogenetically distinct hepatitis $\mathrm{E}$ viruses in Pakistan. American Journal of Tropical Medicine and Hygiene 62: 187-189.

Dai X et al., 2013. Hepatitis E virus genotype 4, Nanjing, China, 2001-2011. Emerging Infectious Diseases 19: 1528-1530.

Donnelly MC et al., 2017. Hepatitis E-a concise review of virology, epidemiology, clinical presentation and therapy. Aliment Pharmacology Therapeutics 46: 126141.

Dalton HR et al., 2014. Hepatitis E virus: Current concepts and future perspectives. Current Infectious Disease Reports 16: 399 .

Dalton SW et al., 2008. Autochthonous hepatitis E in Southwest England: Natural history, complications and seasonal variation, and hepatitis E virus IgG seroprevalence in blood donors, the elderly and patients with chronic liver disease. European Journal of Gastroenterology and Hepatology 20: 784-790.

Debing $\mathrm{Y}$ et al., 2016. Update on hepatitis E virology: Implications for clinical practice. Journal of Hepatology 65: 200-212.

Drexler JF et al., 2012. Bats worldwide carry hepatitis E virus-related viruses that form a putative novel genus within the family Hepeviridae. Journal of Virology 86(17): 9134-9147.

Emerson SU et al. 2010. Release of genotype 1 hepatitis E virus from cultured hepatoma and polarized intestinal cells depends on open reading frame 3 protein and requires an intact PXXP motif. Journal of Virology 84: 9059-9069.

Enouf $\mathrm{V}$ et al. 2006. Validation of single real-time TaqMan PCR assay for the detection and quantitation of four major genotypes of hepatitis E virus in clinical specimens. Journal of Medical Virology 78: 1076-1082.

Galiana $C$ et al., 20o8. Occupational exposure to hepatitis $\mathrm{E}$ virus (HEV) in swine workers. American Journal of Tropical Medicine and Hygiene 78: 1012-1015.

Gao S et al., 2015. Surveillance of hepatitis E virus contamination in shellfish in China. International Journal of Environmental Research and Public Health 12: 2026-2036. 
Germany, 1996-2011. Hepatology 60: 1180-1186.

Geurtsvankessel $\mathrm{CH}$ et al., 2013. Hepatitis E and GuillainBarre syndrome. Clinical Infectious Diseases 57: 13691370.

Graff $\mathrm{J}$ et al., 2006. A bicistronic subgenomic mRNA encodes both the $\mathrm{ORF}_{2}$ and $\mathrm{ORF}_{3}$ proteins of hepatitis E virus. Journal of Virology 80: 5919-5926.

Guerra JAAA et al., 2017. Hepatitis E: A literature review. Journal of Clinical and Translational Hepatology 5: 376-383.

Herremans $\mathrm{M}$ et al., 2007. Swine-like hepatitis E viruses are a cause of unexplained hepatitis in the Netherlands. Journal of Virology and Hepatology 14: 140-146.

Hinjoy S et al., 2013. A cross-sectional study of hepatitis E virus infection in healthy people directly exposed and unexposed to pigs in a rural community in northern Thailand. Zoonoses Public Health 6o: 555-562.

Hogema BM et al., 2014. Past and present of hepatitis E in the Netherlands. Transfusion 54:3092-3096.

Holm DK et al., 2015. Declining prevalence of hepatitis E antibodies among Danish blood donors. Transfusion 55: 1662-1667.

Hoofnagle JH et al., 2012. Hepatitis E. New England Journal of Medicine 367: 1237-1244.

Ishida $S$ et al., 2012. Detection and molecular characterization of hepatitis E virus in clinical, environmental and putative animal sources. Archive Virology 157: 2363-2368.

Jia $\mathrm{Z}$ et al., 2014. Epidemiology of hepatitis $\mathrm{E}$ virus in China: Results from the Third National Viral Hepatitis Prevalence Survey, 2005-2006. PLoS One 9: ello837.

Kabrane-Lazizi Y et al., 1999. Evidence that the genomic RNA of hepatitis E virus is capped. Journal of Virology 73: 8848-8850.

Kamar $\mathrm{N}$ et al., 2011. Factors associated with chronic hepatitis in patients with hepatitis $\mathrm{E}$ virus infection who have received solid organ transplants. Gastroenterology 140: 1481-1489.

Kamar $\mathrm{N}$ et al., 2008. Hepatitis $\mathrm{E}$ virus and chronic hepatitis in organ-transplant recipients. The New England Journal of Medicine 358: 811-817.

Kamar $\mathrm{N}$ et al., 2020. Ribavirin for hepatitis $\mathrm{E}$ virus infection after organ transplantation: A large European retrospective multicenter study. Clinical Infectious Diseases 71: 1204-1211.

Khuroo MS and Khuroo MS, 2016. Hepatitis E: An emerging global disease - from discovery towards control and cure. Journal of Virology and Hepatology 23: 68-79.

Kim YM et al., 2011. The first case of genotype 4 hepatitis E related to wild boar in South Korea. Journal of Clinical Virology 50: 253-256.

Koning $\mathrm{L}$ et al., 2013. Clinical implications of chronic hepatitis $\mathrm{E}$ virus infection in heart transplant recipients. The Journal of Heart and Lung Transplantation 32: 78-85.

Koot $\mathrm{H}$ et al., 2015. Frequent hepatitis $\mathrm{E}$ in the Netherlands without traveling or immunosuppression. Journal of Clinical Virology 62: 38-40.
Krumbholz A et al., 2012. Prevalence of hepatitis E virusspecific antibodies in humans with occupational exposure to pigs. Medical Microbiology and Immunology 201: 239-244.

La Rosa G et al., 2011. Hepatitis E virus in Italy: Molecular analysis of travel-related and autochthonous cases. Journal of General Virology 92: 1617-1626.

Labrique A et al., 2010. The global impact of hepatitis E: New horizons for an emerging virus. In: Grayson L (editor), Emerging Infections. 9. American Society for Microbiology, Washington, DC, USA; pp: 54-92.

Lagler $\mathrm{H}$ et al., 2014. Hepatitis $\mathrm{E}$ virus seroprevalence in Austrian adults: A nationwide cross-sectional study among civilians and military professionals. PLoS One 9: e87669.

Lee GH et al., 2016. Chronic infection with camelid hepatitis $\mathrm{E}$ virus in a liver transplant recipient who regularly consumes camel meat and milk. Gastroenterology 150: 355-357.

Li SW et al., 2015. The development of a recombinant hepatitis E vaccine HEV 239. Human Vaccines and Immunotherapeutics 11: 908-914.

Lozano R et al., 2012. Global and regional mortality from 235 causes of death for 20 age groups. The Lancet 380 : 2095-2128.

Lu L et al., 2006. Phylogenetic analysis of global hepatitis E virus sequences: Genetic diversity, subtypes and zoonosis. Reviews in Medical Virology 16: 5-36.

Masclaux FG et al., 2013. High occurrence of hepatitis E virus in samples from wastewater treatment plants in Switzerland and comparison with other enteric viruses. Water Research 47: 5101-5109.

Miyashita K et al., 2012. Three cases of acute or fulminant hepatitis $\mathrm{E}$ caused by ingestion of pork meat and entrails in Hokkaido, Japan: Zoonotic food-borne transmission of hepatitis $\mathrm{E}$ virus and public health concerns. Hepatology Research 42: 870-878.

Moal V et al., 2013. Infection with hepatitis $\mathrm{E}$ virus in kidney transplant recipients in southeastern France. Journal of Medical Virology 85: 462-471.

Mokhtari $C$ et al., 2013. Comparison of real-time RT-PCR assays for hepatitis $\mathrm{E}$ virus RNA detection. Journal of Clinical Virology 58: 36-40.

Nagashima $S$ et al., 2017. Characterization of the quasienveloped hepatitis $\mathrm{E}$ virus particles released by the cellular exosomal pathway. Journal of Virology 91(22): eoo822-17; doi: 10.1128/jVLoo822-17.

Nelson KE et al., 2014. Hepatitis E vaccine to prevent morbidity and mortality during epidemics. Open Forum Infectious Diseases 1: ofuog8.

Pavio $\mathrm{N}$ et al., 2015. Zoonotic origin of hepatitis E. Current Opinion in Virology 10: 34-41.

Péron JM et al., 2006. Hepatitis E is an autochthonous disease in industrialized countries: Analysis of 23 patients in South-West France over a 13-month period and comparison with hepatitis A. Gastroenterology and Clinical Biology 30: 757-762.

Pischke $\mathrm{S}$ et al., 2013. Ribavirin treatment of acute and chronic hepatitis E: A single-centre experience. Liver International 33(5): 722-726. 
Preiss JC et al., 2006. Autochthonous hepatitis E virus infection in Germany with sequence similarities to other European isolates. Infection 34: 173-175.

Reuter G et al., 2009. Characterization and zoonotic potential of endemic hepatitis E virus (HEV) strains in humans and animals in Hungary. Journal of Clinical Virology 44: 277-281.

Rutjes SA et al., 2009. Sources of hepatitis E virus genotype 3 in The Netherlands. Emerging Infectious Diseases 15: 381-387.

Salines $\mathrm{M}$ et al., 2017. From the epidemiology of hepatitis E virus (HEV) within the swine reservoir to public health risk mitigation strategies: A comprehensive review. Veterinary Research 48: 1-15.

Shuval H, 2003. Estimating the global burden of thalassogenic diseases: Human infectious diseases caused by wastewater pollution of the marine environment. Journal of Water Health 1: 53-64.

Siddharth S et al. 2017. Hepatitis E virus genotypes and evolution: Emergence of camel hepatitis E variants. International Journal of Molecular Science 18: 869.

Sridhar S et al., 2018. Rat hepatitis E virus as cause of persistent hepatitis after liver transplant. Emerging Infectious Diseases 24: 2241.

Takahashi $\mathrm{K}$ et al., 2004. Complete or near-complete nucleotide sequences of hepatitis $\mathrm{E}$ virus genome recovered from a wild boar, a deer, and four patients who ate the deer. Virology 330: 501-505.

Tedder RS et al., 2016. Virology, serology, and demography of hepatitis $\mathrm{E}$ viremic blood donors in South East England. Transfusion 56: 1529-1536.

Versluis $J$ et al., 2013. Hepatitis E virus: An underestimated opportunistic pathogen virusspecific antibodies in pigs in Germany. Veterinary Microbiology 167: 394-402.

World Health Organization 2020. https://www.who.int/ news-room/fact-sheets/detail/hepatitis-e.

Woo PC et al. 2016. New hepatitis E virus genotype in Bactrian camels, Xinjiang, China, 2013. Emerging Infectious Diseases 22: 2219-2221.

Woo PCY et al., 2014. New hepatitis E virus genotype in camels, the Middle East. Emerging Infectious Diseases 20(6): 1044-1048.

Zhai L et al., 2006. Hepatitis E virus genotyping based on full-length genome and partial genomic regions. Virus Research 120: 57-69.

Zhao Y et al., 2016. Viral hepatitis vaccination during pregnancy. Human Vaccines \& Immunotherapeutics 12: 894-902.

Zhu FC et al., 2010. Efficacy and safety of a recombinant hepatitis $\mathrm{E}$ vaccine in healthy adults: A large-scale, randomised, double-blind placebo-controlled, phase 3 trial. The Lancet 376: 895-902. 